\title{
PENGARUH PEMBELAJARAN KOOPERTIF TIPE STAD TERHADAP KEMAMPUAN PEMAHAMAN DAN KOMUNIKASI MATEMATIS SISWA SEKOLAH DASAR
}

\author{
Rayi Siti Fitriani, M.Pd \\ STKIP Subang \\ ray.fit@yahoo.com
}

\begin{abstract}
Examined the differences in mathematical ability of understanding and communication between students and Cooperative Learning STAD and students in hands-on learning. The subjects were students of class IV SDN Sarimulya II Cikampek. The study concluded: 1) The ability of the final mathematical understanding of students who received different STAD cooperative learning with the ability of students who received direct instruction. 2) The ability of mathematical communications students getting the same STAD cooperative learning with students getting hands-on learning. 3) Increased understanding of the mathematical ability of students who received STAD cooperative learning does not differ greatly from the ability of the students who received direct instruction. 4) Improving students' mathematical communication skills that got STAD cooperative learning significantly better than students who received direct instruction.
\end{abstract}

Keywords: Cooperative learning STAD type, mathematical understanding and communication capabilities

ABSTRAK

Bertujuan menelaah perbedaan kemampuan pemahaman dan komunikasi matematis antara siswa dengan pembelajaran Kooperatif tipe STAD dan siswa pada pembelajaran langsung. Subjek penelitian adalah siswa kelas IV SDN Sarimulya II Cikampek. Hasil penelitian menyimpulkan:1)Kemampuan pemahaman matematis akhir siswa yang mendapat pembelajaran kooperatif tipe STAD berbeda dengan kemampuan siswa yang mendapat pembelajaran langsung. 2)Kemampuan komunikasi matematis siswa yang mendapat pembelajaran kooperatif tipe STAD sama dengan siswa yang mendapat pembelajaran langsung. 3)Peningkatan kemampuan pemahaman matematis siswa yang mendapat pembelajaran 
kooperatif tipe STAD tidak berbeda jauh dari kemampuan siswa yang mendapat pembelajaran langsung. 4)Peningkatan kemampuan komunikasi matematis siswa yang mendapat pembelajaran kooperatif tipe STAD lebih baik secara signifikan dibandingkan dengan siswa yang mendapat pembelajaran langsung.

Kata Kunci : Pembelajaran Kooperatif Tipe STAD, kemampuan pemahaman dan komunikasi matematis

Pendahuluan

Matematika merupakan ilmu yang memiliki peranan penting dalam berbagai disiplin dan dalam mendasari kemajuan teknologi dewasa ini. Oleh karena itu matematika perlu diperkenalkan sejak dini kepada anak-anak. Dalam BSNP (2006) dijelaskan bahwa mata pelajaran matematika perlu diberikan kepada peserta didik mulai dari sekolah dasar untuk membekali peserta didik dengan kemampuan berpikir logis, analitis, sistematis, kritis dan kreatif, serta kemampuan bekerjasama. Hal ini tidak lain agar peserta didik memiliki kemampuan untuk dapat bertahan hidup pada keadaan yang dinamis dan kompetitif. Untuk mencapai tujuan di atas, maka baik pemerintah maupun praktisi yang terkait pada bidang pendidikan melakukan berbagai usaha berbagai bentuk penyempurnaan yang berkaitan dengan pendidikan agar kemampuan yang diharapkan tercapai termasuk pada segi pembelajaran.
Merujuk pada tujuan pembelajaran matematika di sekolah dasar dalam KTSP tahun 2006, disebutkan ada beberapa kemampuan yang harus dimiliki oleh siswa (Depdiknas, 2006 : 417) yaitu:

1. Memahami konsep matematika, menjelaskan keterkaitan antar konsep dan mengaplikasikan konsep atau algoritma, secara luwes, akurat, efisien, dan tepat, dalam pemecahan masalah

2. Menggunakan penalaran pada pola dan sifat, melakukan manipulasi matematika dalam membuat generalisasi, menyusun bukti, atau menjelaskan gagasan dan pernyataan matematika

3. Memecahkan masalah yang meliputi

memahami

kemampuan merancang masalah, matematika, menyelesaikan model dan menafsirkan solusi yang diperoleh

4. Mengomunikasikan gagasan dengan simbol, tabel, diagram, atau media lain untuk memperjelas keadaan atau masalah 
5. Memiliki sikap menghargai kegunaan matematika dalam kehidupan, yaitu memiliki rasa ingin tahu, perhatian, dan minat dalam mempelajari matematika, serta sikap ulet dan percaya diri dalam pemecahan masalah.

Namun, pencapaian hasil belajar matematika di Indonesia belum dikatakan berhasil. Dalam laporan Trends in International Mathematics and Science Study (TIMSS) tahun 2011 menyebutkan bahwa Indonesia berada pada posisi ke-38 dari 42 negara yang siswanya di tes, skor Indonesia turun 11 poin dari penilaian pada tahun 2007 (http://edukasi.kompas.com/read /2012/12/14/09005434)

Terkait dengan kemampuan yang seyogyanya dikuasai oleh siswa, Lim, L dan Pugalee, D. (2004), menyebutkan dari keempat kategori kemampuan yang dievaluasi (pengetahuan, aplikasi,

berfikir/inquiry/pemecahan

masalah, komunikasi), prestasi siswa yang paling rendah terdapat pada kemampuan komunikasi dalam hal ini komunikasi matematika, dengan hanya mencapai $13 \%$. Pencapaian hasil belajar dan pencapaian kemampuan dasar yang kurang memuaskan di Indonesia ini dapat disebabkan oleh beberapa faktor salah satunya ialah penekanan kurikulum dalam pendekatan dan proses matematika. Dalam laporan TIMSS tahun 2003 memperlihatkan perbedaan penekanan pada beberapa aspek instruksi matematika diantara negara-negara peserta TIMSS. Adapun laporannya adalah sebagai berikut.

\section{Penekanan pada Pendekatan dan Proses dalam Kurikulum Matematika}

\begin{tabular}{llr}
\multicolumn{2}{c}{ Laporan TIMSS atas } \\
memperlihatkan bahwa di \\
Indonesia perhatian pada \\
komunikasi matematika masih \\
tergolong sangat sedikit, \\
sedangkan NCTM
\end{tabular}
menyatakan bahwa kemampuan komunikasi matematika adalah essential part dalam matematika dan pendidikan matematika. Wahyudin (2012) menjelaskan komunikasi merupakan cara berbagi gagasan dan mengklasifikasi pemahaman. Dengan mengkomunikasikan hasil pemikiran mereka kepada orang lain baik secara lisan maupun tulisan, mereka belajar bagaimana untuk meyakinkan orang lain, mengkontruksi pemahaman mereka sendiri, sehingga siswa lebih memahami konsep yang diajarkan. Sejalan dengan hal tersebut Bruner (Suryadi, D.: 2010) menjelaskan bahwa belajar, merefleksikan suatu proses sosial yang di dalamnya anak terlibat dalam dialog dan diskusi baik dengan diri mereka sendiri maupun 
orang lain termasuk guru sehingga mereka berkembang secara intelektual.

Kemampuan komunikasi matematis siswa saling berkaitan dengan

kemampuan pemahaman matematisnya. Seperti apa yang dikemukakan oleh Cai, Lane, dan Jakabscin (1996) bahwa untuk mengembangkan kemampuan komunikasi diperlukan pemahaman matematis yaitu pemahaman terhadap konsep, prinsip, dan strategi penyelesaian.

Berlandaskan dari harapan yang ingin dicapai pada pembelajaran matematika dengan kenyataan di lapangan, maka untuk mengembangkan kedua kemampuan tersebut tentu perlu diciptakan suatu setting pembelajaran yang dapat mendukung

Sumarmo (2005) mengatakan agar pembelajaran dapat memaksimalkan proses dan hasil belajar matematika, guru perlu mendorong siswa untuk terlibat secara aktif dalam diskusi, bertanya serta menjawab pertanyaan, berpikir secara kritis, menjelaskan setiap jawaban yang diberikan, serta mengajukan alasan untuk setiap jawaban yang diajukan. Sesuai dengan apa yang dipaparkan oleh Anthony, G. Dan Walshay, M. Dalam Effective Pedagogy in Mathematica (2009) menyebutkan bahwa guru yang efektif memberikan para siswa dengan kesempatan untuk bekerja secara mandiri dan bersama-sama untuk memahami ide. Merujuk pada teori Vygotsky (Suryadi, D. 2010) diperoleh tiga hal utama yang berkaitan dengan pembelajaran yaitu:

1) Pembelajaran efektif mengarah kepada perkembangan

2) Pembelajaran efektif akan berhasil dikembangkan melalui setting pemecahan masalah

3) Pembelajaran efektif berfokus pada upaya membantu siswa untuk mencapai Potential Development

Menyadari akan pentingnya keaktifan siswa untuk mengembangkan kemampuan pemahaman dan komunikasi matematis maka perlu memilih model atau pendekatan pembelajaran yang tepat yang mengarahkan siswa pada pembelajaran berkelompok untuk menciptakan diskusi. Pembelajaran yang dirasakan tepat ialah pembelajaran kooperatif. Kramarski (2000: 168) menyatakan bahwa aktivitas belajar siswa dalam kelompok kecil memberikan kesempatan kepada siswa untuk melakukan komunikasi matematik melalui sejumlah pertanyaan metakognitif yang terfokus kepada sifat permasalahan, membangun pengetahuan sebelumnya 
dengan pengetahuan yang baru, dan penggunaan strategi yang tepat dalam memecahkan masalah. Pembelajaran yang mengarahkan siswa pada setting pembelajaran dalam kelompok kecil disebut dengan pembelajaran kooperatif atau kolaboratif.

Pembelajaran kooperatif memiliki berbagai macam tipe, salah satunya STAD. Slavin (2005: 143) menjelaskan bahwa STAD merupakan salah satu metode pembelajaran kooperatif yang paling sederhana dan baik untuk permulaan bagi guru yang menggunakan pendekatan kooperatif. Pembelajaran kooperatif tipe STAD dirasakan tepat bagi kelas yang masih asing atau jarang terhadap pembelajaran diskusi atau berkelompok. Sehingga lebih memudahkan dalam menjelaskan aturan pembelajaran pada setting yang baru. Wahyudin (2012: 350) menjelaskan bahwa pada pengalaman pertama pada siswa dengan belajar kooperatif, guru menjelaskan bahwa mereka tidak akan belajar sendiri melainkan bekerja dalam kelompok untuk menyelesaikan suatu aktivitas. Yang perlu diperhatikan ialah bahwa dalam pembelajaran kooperatif mereka akan membantu orang lain sambil mereka bekerja sendiri. Pernyataan ini sesuai dengan pernyataan Jolliffe, W.(2007:3) yang menyatakan bahwa para peneliti sepakat bahwa untuk menjadi benar-benar kooperatif, pembelajaran sejatinya terdiri dari elemen kunci dan dua hal yang amat penting yaitu Positive interdependent (ketergantungan yang positif) dan Individual accountability (tanggung jawab individu). Johnson dan Johnson (2007: 4) menyebutkan terdapat dua macam ketergantungan sosial (social interdependent), yaitu positif (kooperatif/kerjasama) dan negatif (kompetisi).

Berdasarkan paparan di atas, penulis tertarik untuk melakukan suatu penelitian eksperimen dalam meningkatkan kemampuan pemahaman dan komunikasi matematis dengan melihat pengaruh pembelajaran kooperatif tipe STAD. Namun, agar penelitian ini tidak meluas, maka pada pembelajaran matematika yang menjadi fokus penelitian yang akan dilakukan ialah pada konsep pecahan. Hal ini dipilih atas pertimbangan bahwa pecahan selalu menjadi tantangan yang cukup berat bagi siswa bahkan hingga sekolah menengah. Wearne dan Kouba (Van De Walle, 2007: 35) melaporkan bahwa hasil dari tes NAEP secara konsisten telah menunjukkan bahwa para siswa memiliki pemahaman yang lemah terhadap konsep pecahan. Kelemahan pada konsep pecahan tersebut, 
dikhawatirkan

dapat

mengakibatkan kesulitan pada tahapan memperoleh konsep selanjutnya seperti konsep desimal dan persen, penggunaaan pecahan pada pengukuran dan konsep rasio dan proporsi.

\section{Berdasarkan}

permasalahan di atas maka

\begin{tabular}{|cccc|}
\hline Kelomp & Prete & Perlaku & Poste \\
ok & st & an & st \\
A & O & X & O \\
B & O & & O \\
\hline
\end{tabular}

rumusan masalah dalam

penelitian ini adalah:

1. Apakah terdapat perbedaan kemampuan pemahaman dan komunikasi matematis antara kelas yang mendapat pembelajaran kooperatif tipe STAD dengan kelas yang mendapat pembelajaran langsung (direct instructions) kemampuan pemahaman dan representasi matematis siswa yang mendapatkan pembelajaran kontekstual lebih tinggi daripada kemampuan pemahaman siswa yang mendapatkan direct instruction.

2. Apakah terdapat perbedaan peningkatan kemampuan pemahaman dan komunikasi matematis antara kelas yang mendapat pembelajaran kooperatif tipe STAD dengan kelas yang mendapat pembelajaran langsung (Direct Instructions)

\section{Metode}

Metode yang digunakan dalam penelitian ini adalah metode eksperimen dengan menggunakan desain eksperimen kuasi dengan nonequivalent groups pretestposttets design. Desain metode eksperimen kuasi bentuk nonequivalent groups pretestposttets design (Sugiono, 2011: 116) ini dapat digambarkan sebagai berikut :

\section{Nonequivalent Groups Pretest- Posttets}

Keterangan:
$\mathrm{A}=$ Kelompok Eksperimen
$\mathrm{B}=$ Kelompok Kontrol
$\mathrm{O}=$ Pretest $=$ Postest
$X=$ Perlakuan pembelajaran matematika dengan model Kooperatif tipe STAD

Penelitian ini dilaksanakan di SDN Sarimulya 2 Kotabaru Kec. Cikampek Kab. Karawang. Populasi dari penelitian ini ialah seluruh siswa kelas IV SDN Sarimulya 2 pada Tahun ajaran 2012/2013. Pengambilan sampel dalam penelitian ini menggunakan teknik purposive sampling. Teknik purposive sampling adalah teknik penentuan sampel dengan pertimbangan tertentu (Sugiyono, 2010). Sampel dalam penelitian ini adalah dua kelompok siswa di kelas IV-A 
dan IV-B, dengan perlakuan siswa kelas IV-A sebagai kelas eksperimen dan kelas IV-B sebagai kelas kontrol.

Untuk memperoleh data dalam penelitian eksperimen ini digunakan satu jenis instrumen penelitian yaitu jenis tes. Tes kemampuan pemahaman dan komunikasi matematis dalam penelitian ini digunakan untuk memperoleh data kuantitatif berupa kemampuan siswa dalam menyelesaikan soal-soal pemahaman matematis dan soal-soal komunikasi matematis. Tes yang digunakan berupa soal uraian sebanyak 10 soal yang mana terdiri dari 5 soal untuk mengukur kemampuan pemahaman matematis siswa dan 5 soal lainnya untuk melihat sejauh mana proses pengerjaan yang dilakukan oleh siswa agar dapat mengetahui kemampuan komunikasi matematis.

Penskoran

untuk pemahaman dan kemampuan komunikasi matematis siswa pada penelitian ini menggunakan pedoman Holistic Scoring Rubrics yang dikembangkan oleh Cai, Lane, dan Jakabesin (1996). Adapun pedoman penskoran tes pemahaman dan komunikasi matematis disajikan pada tabel di bawah ini.

Penskoran untuk Tes

Kemampuan Pemahaman Matematis

\begin{tabular}{|l|l|}
\hline Skor & $\begin{array}{l}\text { Respon Siswa } \\
\text { terhadap Soal }\end{array}$ \\
\hline
\end{tabular}

\begin{tabular}{|c|c|c|c|}
\hline 0 & \multicolumn{3}{|c|}{$\begin{array}{l}\text { Tidak ada jawaban/ } \\
\text { salah } \\
\text { menginterpretasikan }\end{array}$} \\
\hline 1 & \multicolumn{3}{|c|}{$\begin{array}{l}\text { Jawaban sebagian } \\
\text { besar mengandung } \\
\text { perhitungan yang salah }\end{array}$} \\
\hline 2 & \multicolumn{3}{|c|}{$\begin{array}{lr}\text { Jawaban } & \begin{array}{r}\text { kurang } \\
\text { lengkap }\end{array} \\
\text { petunjuk } & \text { diikuti) } \\
\text { penggunaan } & \text { algoritma } \\
\text { lengkap, } & \text { namun } \\
\text { mengnadung } & \\
\text { perhitungan yang salah }\end{array}$} \\
\hline 3 & \multicolumn{3}{|c|}{ 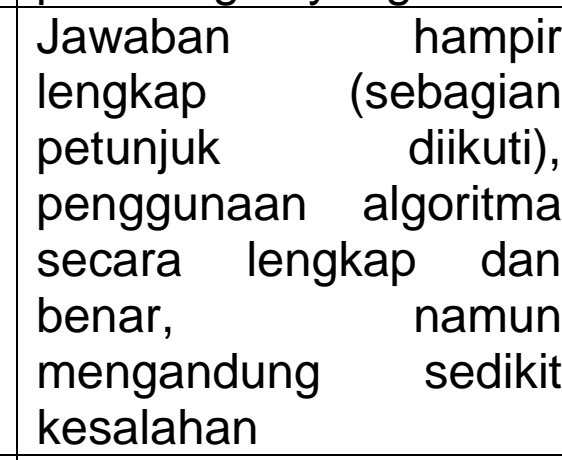 } \\
\hline 4 & \multicolumn{3}{|c|}{$\begin{array}{l}\text { Jawaban lengkap } \\
\text { (hampir semua petunjuk } \\
\text { soal diikuti), } \\
\text { penggunaan algoritma } \\
\text { secara lengkap dan } \\
\text { benar, dan melakukan } \\
\text { perhitungan dengan } \\
\text { benar. }\end{array}$} \\
\hline \multicolumn{4}{|c|}{$\begin{array}{c}\text { Penskoran untuk Tes } \\
\text { Kemampuan Komunikasi } \\
\text { Matematis }\end{array}$} \\
\hline \multirow[b]{2}{*}{$\begin{array}{c}\text { Sko } \\
r\end{array}$} & \multicolumn{3}{|c|}{$\begin{array}{c}\text { Respon Siswa } \\
\text { terhadap Siswa }\end{array}$} \\
\hline & en & $\begin{array}{l}\text { Meng } \\
\text { gam } \\
\text { bar }\end{array}$ & $\begin{array}{c}\text { Eks } \\
\text { pre } \\
\text { si } \\
\text { Mat } \\
\text { em }\end{array}$ \\
\hline J & \multicolumn{3}{|c|}{ dak ada jawaban, } \\
\hline
\end{tabular}


Didaktik : J urnal Pendidikan Guru Sekolah Dasar, ISSN : 2477-5673

Sekolah Tinggi Keguruan dan IImu Pendidikan Subang

Volume I Nomor 1, Desember 2015

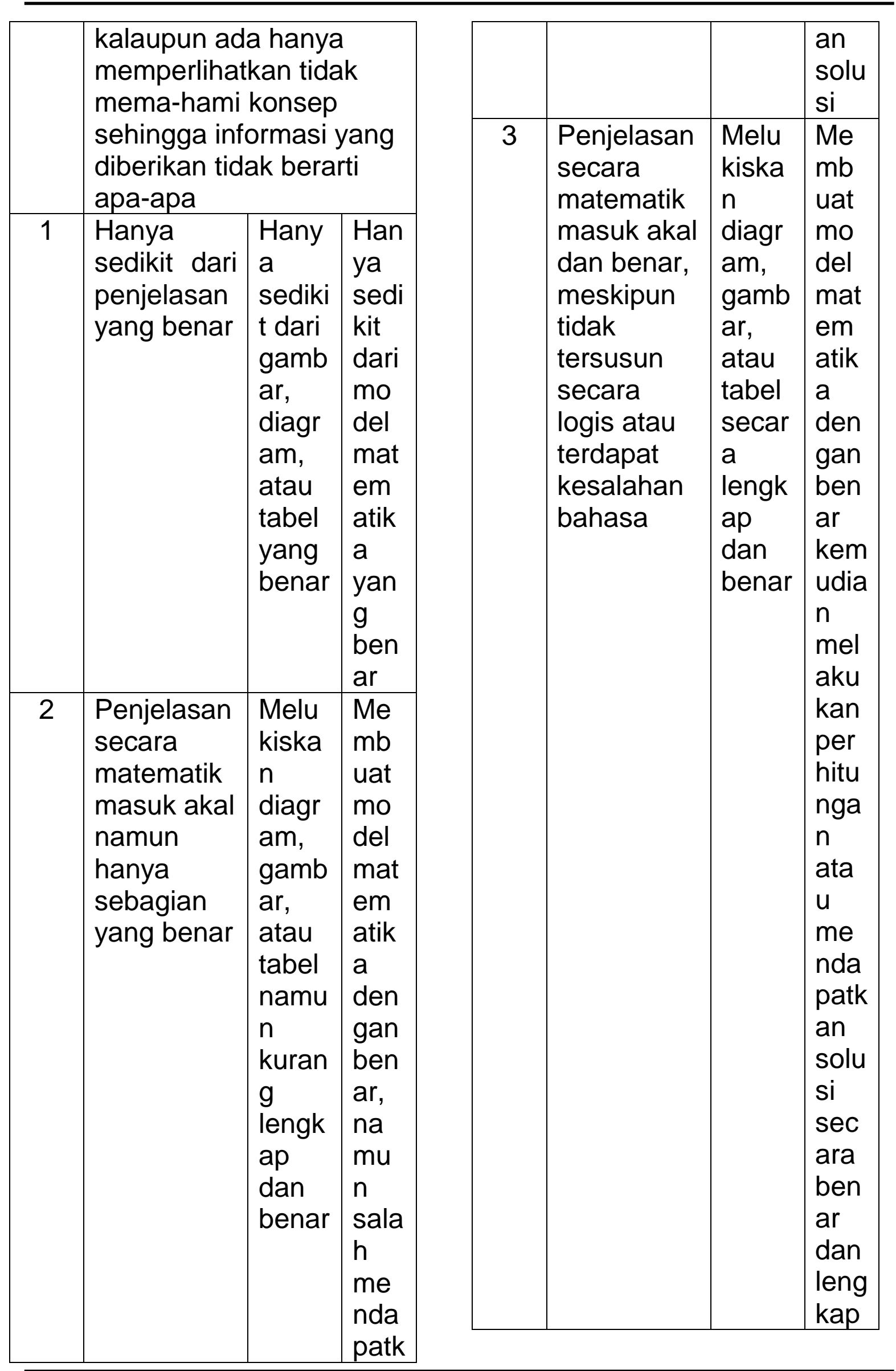


Didaktik : J urnal Pendidikan Guru Sekolah Dasar, ISSN : 2477-5673

Sekolah Tinggi Keguruan dan Ilmu Pendidikan Subang

Volume I Nomor 1, Desember 2015

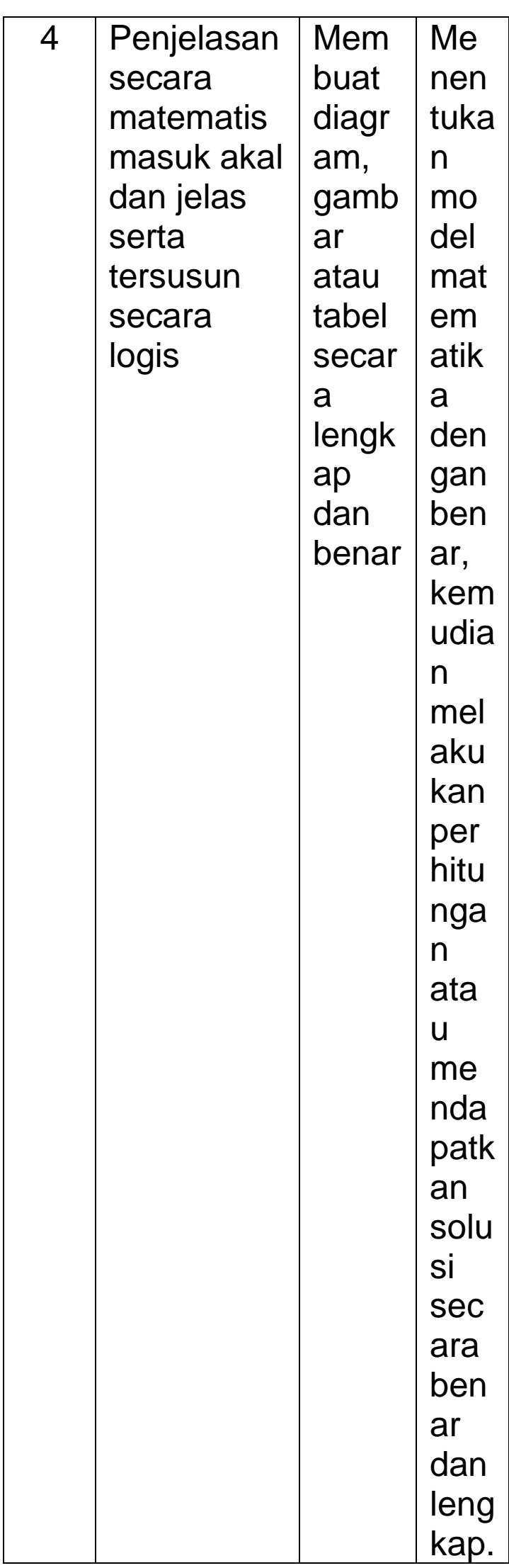

Analisis data pada penelitian ini dibantu oleh SPSS 16 dan
Microsoft Excel 2010. Teknik analisis data dalam penelitian ini dilakukan dengan menggunakan uji statistik dengan tahapan sebagai berikut;

1) Uji normalitas data skor pretes, postes, dan gain ternormalisasi kemampuan pemahaman dan representasi matematis dengan menggunakan uji normalitas KolmogorovSmirnov pada taraf signifikansi 0,05.

2) Uji homogenitas data skor pretes, postes, dan gain ternormalisasi kemampuan pemahaman dan representasi matematis dengan menggunakan uji Homogenitas of Variances (Levene Statistic) dengan taraf signifikansi 0,05.

3) Uji perbedaan dua rata-rata menggunakan uji t Compare Means (Independent- Sample T-Test) dengan taraf signifikansi 0,05.

\section{Hasil dan Pembahasan}

Berdasarkan analisis data terhadap skor rata-rata pretes pada kelas eksperimen yaitu senilai 14,06 atau dan rata-rata pretes pada kelas kontrol senilai 14,23. Perbedaan rata-rata pretes kemampuan pemahaman matematis antara kelas kontrol dan kelas eksperimen tidak begitu jauh. Kelas eksperimen memperoleh skor pretes 31,95\% dari nilai total yang seharusnya. 
Dan kelas kontrol memperoleh skor pretes $32,34 \%$ dari nilai total yang seharusnya. Hal ini menunjukan bahwa secara umum kemampuan pemahaman matematis kelas kontrol dan kelas eksperimen masih rendah.

Hasil analisis penelitian menunjukkan bahwa rata-rata hasil pretes kemampuan pemahaman matematis pada kelas eksperimen dan kelas kontrol tidak jauh berbeda. Kelas eksperimen memiliki rata-rata 4,45 dan kelas kontrol memiliki rata-rata 4,55 .Perbedaannya kelas eksperimen 0,1 lebih rendah dari kelas kontrol. Setelah kegiatan pembelajaran dilaksanakan, diperoleh rata-rata kemampuan pemahaman kelas eksperimen sebesar 16,97 dan rata-rata kemampuan pemahaman kelas kontrol 17,33. Terlihat terjadi perbedaan ratarata antara kelas eksperimen dan kelas kontrol. Perbedaannya kelas eksperimen 0,36 lebih tinggi dari kelas kontrol.

Sedangkan rata-rata hasil pretes kemampuan komunikasi matematis pada kelas eksperimen dan kelas kontrol sama, tidak ada perbedaan. Setelah kegiatan pembelajaran dilaksanakan terjadi perbedaan rata-rata antara kelas eksperimen dan kelas kontrol. Kelas ekperimen memiliki ratarata kemampuan komunikasi sebesar 17,15 dan kemampuan komunikasi kelas kontrol 15,97.
Perbedaannya kelas eksperimen 1,18 lebih tinggi dari kelas kontrol.

Apabila penulis analisis, latar belakang kurang optimalnya pencapaian kemampuan pemahaman matematis siswa kelas eksperimen, antara lain.

1. Jumlah siswa dalam satu kelompok

Dalam penelitian ini, jumalah siswa dalam satu kelompok terdiri dari 5 orang, sedangkan Slavin (2006) menyatakan satu kelompok kecil yang dibentuk untuk pembelajaran kooperatif ialah 4-5 orang. Untuk kelas yang belum pernah atau jarang melakukan pembelajaran kooperatif, dianjurkan untuk membentuk kelompok yang mana satu kelompok terdiri dari 4 orang (dalam hal ini diambil paling sedikit). Pembagian kelompok yang seyogyanya diambil paling sedikit jumlah siswa dalam satu kelompok, agar pembelajaran dalam kelompok kecil berlangsung optimal. Terlihat karena dalam penelitian ini satu kelompok terbentuk dari 5 orang, terlihat masih saja terdapat siswa yang tidak bekerja, yang hanya mengandalkan teman.

2. Keterlibatan Guru

Dalam menerapkan pembelajaran kooperatif tipe 
STAD, peran guru sangat menentukan. Guru harus mampu mengkoordinir suasana kelas, kerja masingmasing kelompok. Guru harus terus meyakinkan pada siswa bahwa pada saat ini mereka bekerja kelompok, tugas mereka adalah teman satu kelompok sama-sama menguasai materi. Oleh karena itu, pembelajaran kooperatif tipe STAD akan lebih optimal diterapkan apabila memiliki guru pendamping, kecuali apabila kondisi jumlah siswa dalam satu kelas masih terbilang sedikit.

3. Waktu

Pada

awal-awal

pembelajaran kooperatif tipe STAD diterapkan, tentu ketidak biasaan terjadi pada siswa. Siswa masih merasa asing pada pembelajaran yang dilakukan. Hal ini tentu membutuhkan waktu yang cukup lama untuk mengantarkan siswa pada setiing pembelajaran berkelompok dan mandiri.

Ada satu hal yang menjadi perhatian penulis yang penulis duga sebagai satu faktor yang perlu digaris bawahi yaitu keterbiasaan siswa belajar mandiri dalam memahami materi pada pelajaran matematika. Selama ini siswa belajar dengan sumber utama yaitu guru, dan masih jarang untuk menerapkan pembelajaran secara mandiri dalam memahami suatu konsep.

Namun

kemampuan komunikasi matematis siswa terlihat meningkat. Selain dari itu dampak positif yang muncul dari siswa ialah terlihat dari perubahan perilaku belajar yang positif. Siswa mulai terbiasa belajar secara mandiri dalam memahami suatu konsep, mampu belajar secara bekerjasama, bersedia dan sabar membantu teman dalam memahami konsep, berani menjelaskan ide, jawaban dan pendapat kepada guru dan teman dengan bahasa sendiri.

\section{Kesimpulan dan Saran}

Berdasarkan hasil penelitian dan pembahasan diperoleh kesimpulan sebagai berikut:

1. Kemampuan pemahaman matematis akhir siswa yang mendapat pembelajaran kooperatif tipe STAD berbeda dengan kemampuan siswa yang mendapat pembelajaran langsung (direct instructions). Hal ini dapat dilihat pada perhitungan hasil postest kedua kelas tersebut, bahwa kelas kontrol lebih baik dari kelas eksperimen. Sedangkan kemampuan komunikasi siswa yang mendapat pembelajaran kooperatif tipe STAD sama dengan 
siswa yang mendapat pembelajaran langsung (direct instruction). Hal ini dapat dilihat pada perhitungan hasil postest siswa, bahwa kelas eksperimen lebih baik dari kelas kontrol.

2. Peningkatan kemampuan pemahaman matematis siswa yang mendapat pembelajaran kooperatif tipe STAD tidak berbeda jauh dari kemampuan siswa yang mendapat pembelajaran langsung (direct instructions). Hal ini dapat dilihat pada perhitungan gain ternormalisasi pada kelas eksperimen tidak jauh berbeda dengan kelas kontrol. Sedangkan peningkatan kemampuan komunikasi matematis siswa yang mendapat pembelajaran kooperatif tipe STAD lebih baik secara signifikan dibandingkan dengan siswa yang mendapat pembelajaran langsung (direct instruction). Hal ini dapat dilihat pada perhitungan gain ternormalisasi pada kelas eksperimen lebih tinggi dibandingkan pada kelas kontrol.

Beberapa saran yang dapat dipertimbangkan untuk proses

pembelajaran

matematika selanjutnya, adalah sebagai berikut.

1. Agar pelaksanaan penelitian lebih tidak bias, maka sebaiknya penelitian dilakukan oleh guru (wali kelas) dari subjek yang diteliti.

2. Untuk kelas yang baru memulai atau belum terbiasa dengan pembelajaran secara berkelompok, sebaiknya membentuk kelompok dengan jumlah anggota yang paling sedikikit (3-4 orang). Hal ini untuk menghindari siswa yang pasif dalam pelaksanaan diskusi kelompok.

3. Bantuan guru pendamping diperlukan dalam penerapan pembelajaran ini, agar lebih bisa mengontrol suasana kelas.

4. Untuk penelitian lebih lanjut hendaknya penelitian ini dapat dilengkapi dengan melakukan penelitian aspekaspek kemampuan matematis yang lain yaitu kemampuan pemecahan masalah, koneksi, dan representasi matematis secara lebih terperinci dan melakukan penelitian di tingkat sekolah yang belum terjangkau oleh peneliti saat ini.

5. Model pembelajaran kooperatif tipe STAD terbukti dapat meningkatkan 
kemampuan komunikasi matematis siswa sekolah dasar. Oleh karena itu, model ini disarankan untuk digunakan guru dalam pembelajaran matematika di sekolah dasar.

\section{Daftar Pustaka}

Anthony, G. Dan Walshay, M.(2009). Effective Pedagogy in Mathematics. Belgia: IAE (International Academy of Education)

Departemen

Pendidikan

Nasional. 2006. Kurikulum 2006 KTSP. Jakarta: Pusat Kurikulum, Balitbang. Depdikbud.

Cai, J., Lane, S., dan Jakabcsin, M.S. (1996). The Role of Open-Ended Tasks and Holistic Scoring Rubrics: Assessing Student's Mathematical Reasoning and Communication. Dalam P.C Elliot dan M.J Kenney (Eds). Yearbook Communication in Mathematics K-12 and Beyond. Reston, VA: The National Council of Teachers of Mathematics.

Jolliffe, W. (2007). Cooperative in The Classroom: Putting it into Practice. London: PCP (Paul Chapman Publishing)

Kramarski. (2000). "The Effect od Different Instructional Methods on The Ability to Communicate
MathematicalReasoning".

Dalam Nahakama, $T$ dan Koyama, M. Proceeding of The $24^{\text {th }}$ Conference of The International Group for The Psychology of Mathematics Education. Hiroshima University

Lim, L., Pugalee, D. (2004). Using Journal Writing to Explore "They Communicate to Learn Mathematics and They Learn to Communicate Mathematically". [Online]. Tersedia:

www.nipissingu.ca/oar/pdfs/ v722.pdf

Napitululu, E.L. (2012). Prestasi Sains dan Matematika Indonesia Menurun. [Online]. Tersedia: http://edukasi.kompas.co $\mathrm{m} / \mathrm{read} / 2012 / 12 / 14 / 09005$ 434

Slavin. (2005). Cooperative Learning: Teori Riset dan Praktik. Bandung: Nusa Media

Sugiyono. (2010). Metode Penelitian Pendidikan. Pendekatan Kuantitatif, Kualitatif, dan $R \& D$. Bandung: Alfabeta

Sumarmo,

$U$. (2004). Pembelajaran Matematika untuk Mendukung Pelaksanaan Kurikulum Berbasis Kompetensi. Makalah pada Pertemuan MGMP Matematika SMPN 
I Tasikmalaya.[12 Februari 2005].

Suryadi, D. (2010). Menciptakan

Proses Belajar Aktif: Kajian dari Sudut Pandang Teori Belajar dan Teori Didaktik. Makalah pada Seminar Nasional Pendidikan Matematika di UNP

Van de Walle, J., (2006). Sekolah Dasar dan Menengah: Matematika Pengembangan dan Pengajaran Jilid I. Jakarta: Erlangga

Wahyudin. (2012). Filsafat dan

Model-model Pembelajaran

Matematika. Bandung: Mandiri 